Background Over the last three years, the MoHP has established sixteen OCMCs in sixteen districts cross Nepal. Each OCMC aims to provide an integrated package of services for survivors of violence through a 'one-door' system. OCMCs are designed to follow a multi-sectoral and locally coordinated approach to provide survivors with a comprehensive range of services including health care, psycho-social counselling, access to safe homes, legal protection, personal security and vocational skills training.

Methods Reports, monitoring visits, national level annual review with stakeholders inclusive of hospitals, Police, Attorney, Ministry of Women, MoHP, Chief District Officers, Representatives from Prime Ministers and Counsel of Ministers, I/NGOs and survivors. Results The district report showed that from October 2013 October 2014, OCMCs have provided essential services required by survivors with 2,273 individuals (2,133 (94\%) women and $140(6 \%)$ men) accessing services. A high percentage of women receiving services $(53.6 \%)$ were victims of intimate partner violence, while $26 \%$ had experienced sexual violence. $16 \%$ had suffered extreme mental abuse and $4.8 \%$ 'other types of violence (trafficking, child marriages). The breakdown of data by agegroup shows that violence is common among women between the ages of 15 and 49 years with 1645 women in this category, suggesting married women as the prime targets.

Conclusions OCMCs are a new and challenging initiative. The challenges can be overcome through improved awareness raising activities; capacity building; survivor follow-up; improved screening and coordinating strategies; and more social protection activities. Supporting the establishment of OCMCs in all 75 districts is essential.

\section{HEALTH PROFESSIONALS' ROLE IN THE HUMANITARIAN DISARMAMENT MOVEMENT AND PREVENTING ARMED VIOLENCE}

Maria Valenti. International Physicians for the Prevention of Nuclear War, Somerville, Massachusetts, USA

\subsection{6/injuryprev-2016-042156.570}

Background Disarmament and war prevention are now widely perceived as humanitarian goals by governments and non-governmental organisations alike. In recent years, "humanitarian disarmament" campaigns have taken on some of the world's worst weapons, including landmines, cluster munitions, small arms, drones, and nuclear weapons.

Description of the problem An evidence-based awareness of the impact of war and all forms of armed violence on public health, documented by health professionals in hospitals and emergency rooms and conveyed through the stories of the victims and their ravaged communities, has catalysed successful campaigns to prohibit the most inhumane weapons and to impose strict new limits on trafficking in others. While the term is relatively new, humanitarian disarmament has been at the heart of health-based organisations' efforts such as the International Committee of the Red Cross and International Physicians for the Prevention of Nuclear War's work for decades. For example, the medical evidence that nuclear war would be a humanitarian catastrophe to which physicians could organise no meaningful response helped mobilise the international community towards a nuclear test ban and nonproliferation.

Results The health facts about nuclear weapons and the devastation they cause have become the foundation of a Humanitarian Pledge to "stigmatise, prohibit and eliminate nuclear weapons" that, at this writing, has been joined by 117 countries. The human consequences of armed violence has been a central concept in achieving landmark treaties and agreements on conventional weapons including the Mine Ban Treaty, the United Nations Programme of Action on Small Arms and Light Weapons, the Convention on Cluster Munitions and the Arms Trade Treaty.

Conclusions Health organisations and agencies have a key role to play in bringing the humanitarian perspective to the development and implementation of policy instruments and agreements designed to prevent armed violence.

\section{ANALYSIS ON THE VIOLENCE PREVALENCE AND PREVENTION STATUS IN CHINA}

Gao Xin, Er Yuliang, Duan Leilei, Wang Yuan, Deng xiao, Ji Cuirong, Ye Pengpeng, Jin Ye, Wang Linhong. National Centre for Non-Communicable Disease Control and Prevention, China Centre for Disease Prevention and Control,Beijing, 100050,China

\subsection{6/injuryprev-2016-042156.571}

Background Violence prevention is the priority of public health; and to master the prevalence state and risk factors of violence is the base to develop the prevention strategies. This study aimed to evaluate the violence prevalence and prevention status in China, and to provide reference for the prevention and control of violence.

Methods Violence data were obtained from the National death surveillance data set and National Injury surveillance system. The laws policies, capacity for data collection, programmes and services for violence prevention were described.

Results The trend of violence mortality has declined during 2006-2013. The mortality has decreased from 1.21/100000 in 2006 to $0.65 / 100000$ in 2013 . decreased by $46.3 \%$. The violence mortality was high in young adult men, while it was high in female infants and old women who were over 85 years. Chinese laws and policies included the strategies on violence prevention, but not integrated. There were lack of the nonfatal violence data. Most of the prevention programmes were limit and transient.

Conclusions The different violence prevention strategies could be implemented according to gender differences. China could carry out more work in the aspects of legislation, data collection and service routinization.

\section{VIOLENCE IN THE HEALTH WORK PLACE SURVEY ABOUT 521 CASES AMONG HEALTH STAFF IN TUNISIA}

Latifa Arfaoui, Mahdi Harzalli, Manel Ben Naima. Ministry of Health, Tunisia

\subsection{6/injuryprev-2016-042156.572}

Background Violence in the health work place is actually a serious problem in Tunisia. This phenomenon can be explained by the weakness of the security measures in the health facilities, but also by other causes such as lack of health staff or equipment which make timeouts very long and create a kind of pressure in the health care settings.

In Tunisia, the overall situation has changed since January 2011 when the revolution occurred; the general situation in the country became characterised of violence and insecurity. Some national actions have been taken by Ministry of Health in late 2011 in order to eliminate this phenomenon in the health care settings. 
Methods The aim of this research is to assess the situation in our health care settings before and after the actions undertaken in 2011. The research was performed from data collected by the Shocroom (strategic health operations centre), freely provided by the public health facilities. We collected 521 cases between 2011 and October 2015.

Results 521 incidents of verbal and/or physical violence against health workers were reported between 2011 and October 2015. The monthly average of incidents between 2011 and 2015 is as follows:

- 8.16 is the mean of incidents of violence against health workers reported to the Shocroom in 2011.

- 14.08 is the mean of incidents of violence against health workers reported to the Shocroom in 2012.

- 11.08 is the mean of incidents of violence against health workers reported to the Shocroom in 2013

- 8 is the mean of incidents of violence against health workers reported to the Shocroom in 2014.

- 10.22 is the mean of incidents of violence against health workers reported to the Shocroom in 2015.

We notice that despite the actions taken by the Ministry of Health, the number of reported attacks is increasing.

The research also found that $80 \%$ of the incidents of violence against health workers reported are physical.

The percentage of physical violence also increased between 2011 and 2015; it is respectively 78\% in 2011 and 90\% in 2015.

The actor of the violence is a relative of a patient in $61 \%$ of cases and in 39\% the patient himself.

Workplace violence affects all health workers, both physicians and nurses, men and women, though some are more at risk than others. Emergency and ambulance staff are more affected by this violence.

$22 \%$ of the incidents reported were followed by a cessation of work. And even when the victims kept working, there were high levels of stress and in some situations assistance from police.

Conclusions Violence towards health workers is a serious problem sometimes hindering the regular activity of health facilities by work interruptions it generates. In most cases, the actors are relatives of patients, which bring us to review the security measures in health settings.

The analysis of our data shows an increase of this flail in 2015, should we review our policies? Should we further strengthen our action plan in collaboration with other stakeholders such as the Ministry of Interior?

\section{DOMESTIC VIOLENCE AGAINST WOMEN IN RUSSIA AND ITS CONSEQUENCES}

Margarita Kachaeva, Ludmila Satianova. Serbsky National Research Centre for Psychiatry and Narcology, Moscow, Russia

\subsection{6/injuryprev-2016-042156.573}

Background Violence against women is a troubling phenomenon in Russia and also one with great social consequences. Many Russian families are a scene of a silent drama - a drama that society, the courts and other institutions are only beginning to learn to confront. The main purpose of this research is to find out origins of crimes in women who are victims of domestic violence.

Methods Clinical, psychological, statistical.

Results Forensic psychiatrists found out that domestic abuse against women is often one of the main causes of crimes of violence in women. A cohort of 8 females was examined by forensic psychiatrists and psychologists. All women were victims of violence and had committed murders of their husbands or partners whose violence towards women escalated in severity. Domestic abuse resulted in so called battered women syndrome. Clinical assessment has revealed depression, anxiety, fear, post traumatic stress disorder, alcohol abuse. At the time of the crime all women revealed depressive states.

Conclusions A research has been carried out on the basis of forensic psychiatric assessment of those women who had a long history of violence by their husbands or partners. The study has revealed the cycle of violence and the risk of women who are victims of domestic violence to become a perpetrators.

\section{ENHANCING COOPERATION OF MEDICAL AND SOCIAL SERVICES TO IMPROVE AID TO VICTIMS OF VIOLENCE IN ZAMBIA}

${ }^{1}$ Robert Mtonga, ${ }^{2}$ Maria Valenti, ${ }^{2}$ Michael Schober, ${ }^{3}$ Maria Valenti, ${ }^{2}$ Stephanie Hametner. 'Zambian Health Workers for Social Responsibility, Lusaka, Zambia; ${ }^{2}$ International Physicians for the Prevention of Nuclear War-Austria (IPPNW Österreich), Linz, Austria; ${ }^{3}$ International Physicians for the Prevention of Nuclear War, Somerville, Massachusetts, USA

\subsection{6/injuryprev-2016-042156.574}

Background In Zambia, gender-based violence (GBV) is on the rise, with one in five women having experienced sexual violence, and domestic violence frequently reported. Zambia has been working to tackle this. At the 66th World Health Assembly Zambia was one of seven countries that introduced a resolution on violence against women and girls and has also introduced national policies on GBV.

Methods A prospective study that was premised on pilot phase that compared a period prior to an intervention with another period following an intervention to study challenges to addressing GBV in Zambia include effective implementation, limited financial and human resources, and lack of public awareness.

Health professionals from Zambia and Austria collaborated to design a research and education project to address these issues and improve care outcomes for victims of interpersonal violence (IPEV). It was designed to build on existing health and social services infrastructures, improve networking among medical and social services, and below-cost. The intervention included training for medical and social service personnel and distribution at key locations of information on services available to IPEV victims.

Results Capitalising on existing resources, linking local services, and developing a low-cost intervention kept costs down in resource poor Zambia, where the annual government per capita health expenditure is US\$32 or about $11 \%$ of the annual national budget. Sustainability was encouraged by engaging local partners. Results: victims of IPEV had improved understanding of available social services; improved networking among partner organisations; new descriptive data about victims, and; for medical participants, improved cross-cultural understanding.

Conclusions Low-cost interventions may improve care for victims of violence in resource-poor settings. Improved cooperation among social service and medical providers may benefit victims of IPEV and also agencies through strengthened relationships and information flow. North-South cooperation should be encouraged at the institutional level. 